\title{
The Beneficial Effects of High-Intensity Laser Therapy and Co-Interventions on Musculoskeletal Pain Management: A Systematic Review
}

\author{
Kamran Ezzati ${ }^{1}$, E-Liisa Laakso ${ }^{2,3^{*}}$, Amir Salari ${ }^{4}$, Anahita Hasannejad ${ }^{5}$, Reza Fekrazad ${ }^{6,7}$, Arash Aris $^{4}$ \\ ${ }^{1}$ Neuroscience Research Center, Poorsina Hospital, Faculty of Medicine, Guilan University of Medical Sciences, Rasht, Iran \\ ${ }^{2}$ Allied Health Mater Research, Brisbane, Australia \\ ${ }^{3}$ School of Allied Health Sciences, Griffith University, Gold Coast, Australia \\ ${ }^{4}$ Department of Orthopaedics, Orthopaedic Research Center, Poursina Hospital, School of Medicine, Guilan University of \\ Medical Sciences, Rasht, Iran \\ ${ }^{5}$ Zahedan University of Medical Sciences, Zahedan, Iran \\ ${ }^{6}$ Department of Dentistry, AJA University of Medical Sciences, Tehran, Iran \\ ${ }^{7}$ Laser Research Center, Dental Faculty, Tehran University of Medical Sciences, Tehran, Iran
}

\section{*Correspondence to}

E-Liisa Laakso, PT, PhD, Senior

Research Fellow

Email:

Liisa.laakso@mater.uq.edu.au

Published online January 18 2020

\begin{abstract}
Introduction: High-intensity laser therapy (HILT) has been used more recently in the therapeutic protocols of pain managements. Adding therapeutic interventions to laser therapy is usual in clinical practice. This study aimed to evaluate the efficacy of HILT and beneficial effects of adding cointerventions to HILT in musculoskeletal pain management.

Methods: The following databases were searched up to August 2018: Medline, PubMed, EMBASE, Cochrane, Google Scholar, Springer and ISI. The keywords of pain, HILT, high power laser therapy, laser therapy, photobiomodulation, physical therapy and rehabilitation were searched. The quality of the articles was assessed using the PEDro scale. The primary measure was pain severity expected to be reported in all studies. Effect size was calculated as standardized mean differences divided by the standard deviation of either the treatment or other group.

Results: Initially 52 potential studies were found. Eighteen of these studies were excluded based on title and abstract. The full text of 34 remaining articles was screened and 15 of the studies were excluded. All included studies had high quality (PEDro $\geq 7$ ). Approximately, $94 \%$ of included articles $(n=18)$ revealed positive effects of HILT on pain. The effect sizes for HILT and placebo/comparator groups were $0.9-9.11$ and $0.21-11.22$ respectively. Also, the differences of effect size between two groups were between 0.03 to 5.85 .

Conclusion: It is early to determine that HILT may be an effective non-invasive agent in the management of musculoskeletal pain, as few studies have shown its clinical efficacy. Adding related co-interventions to HILT may enhance the beneficial effects of laser therapy. The variability of the study methods and outcomes suggests that further long-term follow-up, randomized controlled clinical trials with appropriate methodological design are needed regarding the effectiveness of HILT on pain.

Keywords: Musculoskeletal pain; Laser therapy; Rehabilitation; Intervention.
\end{abstract}

\section{Introduction}

Laser photobiomodulation (PBM) therapy is a non-invasive and painless method of treatment in contemporary physiotherapy which may have both local and systemic effects on the patients. ${ }^{1-4}$ The effect of PBM on tissues depends on such factors as wavelength, irradiation mode (continuous or pulse), pulse duration, pulse time interval, energy fluence, power output and irradiance. ${ }^{1} \mathrm{PBM}$ stimulates cells including pain receptors in peripheral tissues, the immune system and can cause vasodilation and analgesic effects. So it is widely used to reduce patients' pain..$^{1-3}$ Moreover, laser therapy can stimulate repairs to damaged tissues and peripheral nerves leading to neurological regeneration. ${ }^{1,4,5}$

Low-power laser (light) therapy (power $\leq 500 \mathrm{~mW}$ ) can be used to decrease acute and chronic pain, induce recovery of damaged nerves, enhance peripheral circulation and metabolism, and reduce joint inflammation. ${ }^{2,5,6}$ The effects of low-power laser therapy are photochemical not thermal. In a recent review, Cotler et al concluded that

Please cite this article as follows: Ezzati K, Laakso EL, Salari A, Hasannejad A, Fekrazad R, Aris A. The beneficial effects of high-intensity laser therapy and co-interventions on musculoskeletal pain management: a systematic review. J Lasers Med Sci. 2020;11(1):81-90. doi:10.15171/jlms.2020.14. 
low-power laser therapy is a new cost-effective therapy for musculoskeletal pain, which improves the quality of life and reduces financial strains. ${ }^{5}$

High-intensity laser therapy (HILT) has been used more recently in the therapeutic protocols of physiotherapy. ${ }^{1,2,6}$ The main difference between HILT and low-power laser therapy, is that the more powerful beams (power $>500$ $\mathrm{mW}$ ) are irradiated to penetrate deeper, bringing a desired high amount of multi-directional energy to deep tissues in a short time. ${ }^{2,6-10}$ Also, application techniques, the time of treatment and the cost of the device are different between these two generations of the laser therapy. ${ }^{11-13} \mathrm{~A}$ recent systematic review indicated that HILT is effective in reducing musculoskeletal pain. ${ }^{14}$ Adding therapeutic interventions to laser therapy is usual in clinical practice. ${ }^{3,}$ 15-19 Bjordal et al showed that the overall effects of lowpower laser therapy and anti-inflammatory drugs cointerventions, were poorer than those studies without these co-interventions. ${ }^{20}$ On the other hand, Santuzzi et al found that the combined treatment of low-level laser therapy and cyclooxygenase- 2 may have better effects on wound closure and scar organization. ${ }^{21}$

As there are increasing data available regarding the effects of HILT in musculoskeletal injuries, this study was designed to evaluate the literature assessing the influence of adding interventions to HILT on musculoskeletal pain management.

\section{Methods}

Search Strategy and Study Selection

The following databases were searched up to august 2018: Medline, PubMed, EMBASE, Cochrane, google scholar, Springer and ISI Web of Science. The search keywords were pain, high-intensity laser therapy, high-power laser therapy, laser therapy, photobiomodulation, physical therapy and rehabilitation.

Two reviewers (KE, AH) independently identified titles and abstracts related to applying HILT to musculoskeletal pain. The inclusion criteria were: 1 ) randomized clinical trial study 2) reporting visual analogue scale before and after treatment 3) to have minimum two HILT group or HILT plus exercise group and other intervention group 4) language of article was English 5) PEDro scale was $\geq 7$.

\section{Quality Assessment}

The quality of the articles was assessed using the PEDro scale. The 11-point PEDro scale is considered a reliable and valid assessment tool and is the one most often employed for physical treatments. A score of $\geq 7$ is considered to be a study of high methodological quality, while a score of $\leq 5$ is considered to be of low methodological quality. ${ }^{14,22}$ The methodological assessment was performed by two independent reviewers (KE, $\mathrm{AH})$ and the results were compared. If there was a disagreement, the reviewers discussed the quality of the articles until they reached a final consensus and if necessary, a third reviewer made the decision (RF).

Data Extraction

Two reviewers (KE, AH) completed data extraction and evaluated the characteristics of the study, including the intervention program, inclusion/exclusion criteria, initial data, and values for the pain outcome before and after treatment and follow-up. The primary measure was pain severity which should be reported in all studies.

\section{Statistical Analysis}

Because the pain score was continuous outcome data, means and standard deviations of either group were used to calculate the effect size (ES). ES was calculated as standardized mean differences, which is defined as the differences in pain between two groups divided by the SD of either the control group or treatment group.

$$
E S=\frac{m_{1}-m_{2}}{s d}
$$

The difference of effect sizes was calculated via subtraction of ES of the each group to find the more effective interventions ${ }^{5,23,24}$ :

Difference of effect sizes $=\mathrm{ES}_{1}-\mathrm{ES}_{2}$

\section{Results}

The selection process for including studies in this review is shown in Figure 1. Initially 52 potential studies were found. Eighteen of these studies were excluded based on title and abstract. The full text of 34 remaining articles was screened and 15 articles were excluded ${ }^{1-3,6,7,9,10,23-30}$ because: the PEDro score of three studies was $6^{2,3,28}$. Six articles didn't report pain by VAS; it was not possible to estimate ES in two studies ${ }^{1,6,7,9,10,23,24,27}$; two studies ${ }^{29,30}$ were case reports; and two studies did not have at least one another group for comparison. ${ }^{25,26}$

Finally, 19 studies (HILT: 11, +other interventions: 8) were included for qualitative and quantitative assessment. ${ }^{11-13,15-17,19,31-42}$ The characteristics of all studies in two groups are listed in Table 1.

Technical parameters of HILT are provided in Table 2. Although a maximum power of $8000 \mathrm{~W}$ was reported in two studies, the average power of the lasers used in the reviewed studies was between 0.6 to $25 \mathrm{~W}$. The majority of the studies $(68 \%)$ used pulsed laser PBM with energy density varying from 0.25 to $150 \mathrm{~J} / \mathrm{cm}^{2}$.

All included studies were of high quality (PEDro $\geq 7$ ) (Table 3). Approximately $94 \%$ of the included articles $(n=18)$ revealed positive effects of the HILT on pain.

The effect sizes of the included studies and the differences of the effect sizes are presented in Table 4 . The effect sizes presented are calculated according to the pain outcome. The effect sizes for HILT and placebo/ comparator groups were 0.9-9.11 and 0.21-11.22, respectively. The values of the effect size according to Cohen classification are: small (0.2-0.5), moderate (0.5- 


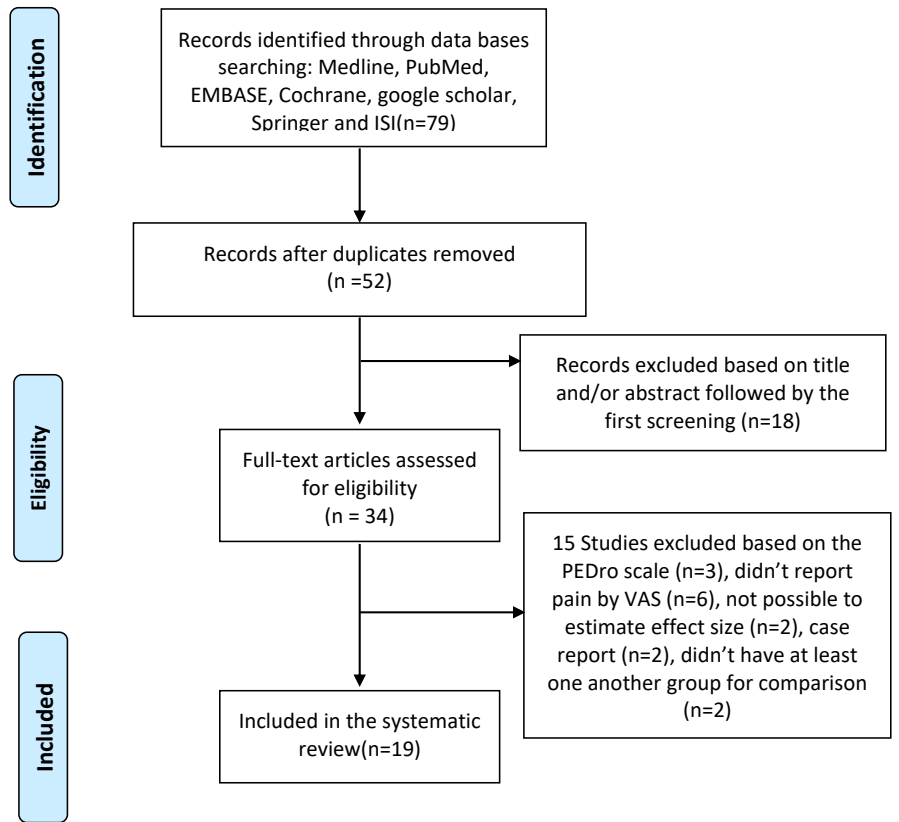

Figure 1. Chart of Screening and Search History.

$0.8)$, and large $(>0.8)^{44-47}$ meaning that the more the ES, the more the impact of the intervention. ${ }^{23,48}$ According to the present study, the difference in the ES for pain assessment was between 0.03 and 5.85. The difference of the ES in 3 numbers of comparisons were in favour of other groups rather than HILT group (see online Supplementary file 1, Table S1). The positive effect of HILT was shown as high ES difference in the 13 trials.

The results of the most to least efficacy of HILT in both groups are indicated in Table 4 . However, in the HILT and exercise group the most effects of HILT were on osteopenia and the least on the Lateral epicondylitis. On the other hand, the most and least effects of HILT with co-interventions were on the chronic back pain and low back with unilateral leg pain respectively (Table 4 ).

\section{Discussion}

Musculoskeletal pain is the main cause of the chronic pain in adults. ${ }^{5}$ The treatment options for reducing musculoskeletal pain are surgical and non-surgical interventions. ${ }^{49}$ The results of this review showed that HILT is widely used in management of chronic pain recently but the laser dosage and power outputs are very different in the patients.

In the first group of classification (HILT and exercise) 4 studies $^{14,32,34,35}$ were about spinal pain which were matched to another group. ${ }^{16-18,20}$ The average of the effect size differences was higher in the first group (1/08) for spinal pain patients. In contrast, the effect size in second group of studies was higher for knee pain patients. Other diseases in both groups were not the same e.g. the plantar fasciitis was surveyed in the first group ${ }^{13}$ or the Juvenile rheumatoid arthritis was evaluated in second group only. ${ }^{42}$ Also, the best effect in the first group was on plantar fascia ${ }^{13}$ and osteopenia. ${ }^{43}$ In the second group, the best outcomes have been shown in Juvenile rheumatoid arthritis ${ }^{42}$ and chronic back pain patients. ${ }^{16}$

The studies that demonstrated positive effects of HILT on pain have some common features as follows: patients were monitored over a long period of time (up to 3 months); higher amounts of energy were used with the average power of 3 and $25 \mathrm{~W}$; the patients most commonly did not use other interventions with laser therapy; and the PBM therapy pulsed for at least ten sessions. ${ }^{39,42,43}$ HILT was more effective in the management of pain in patients with lumbar disc protrusion, ${ }^{18}$ plantar fasciitis, ${ }^{13}$ Children with Juvenile rheumatoid arthritis, ${ }^{42}$ children with haemophilic arthropathy, ${ }^{39}$ males with osteopenia orosteoporosis, ${ }^{43}$ and low back pain..$^{32}$ Conversely, the studies which did not supporting a positive effect of HILT (low differences in ES) most commonly did not specify the amount of introduced energy or the simultaneous consumption of non-steroid anti-inflammatory drugs, so it was not possible to make a judgment on whether the energy parameters may have contributed to a suboptimal outcome. ${ }^{34,36,41}$ The consumption of non-steroid anti-inflammatory drugs may be a confounding factor in evaluating the effects of laser therapy, as identified in some studies ${ }^{13,41}$ Some studies did not mention the effects of disease chronicity, despite the fact that this is a major factor in determining the amount of energy density and power output which is needed in the treatment protocol by laser therapy. ${ }^{13,18,32-34,36,38,41,42}$

It seems that adding thermal and non-thermal agents to HILT may enhance the effects of laser therapy. ${ }^{16,38-40,42}$ The Management of acute and chronic pain is based 


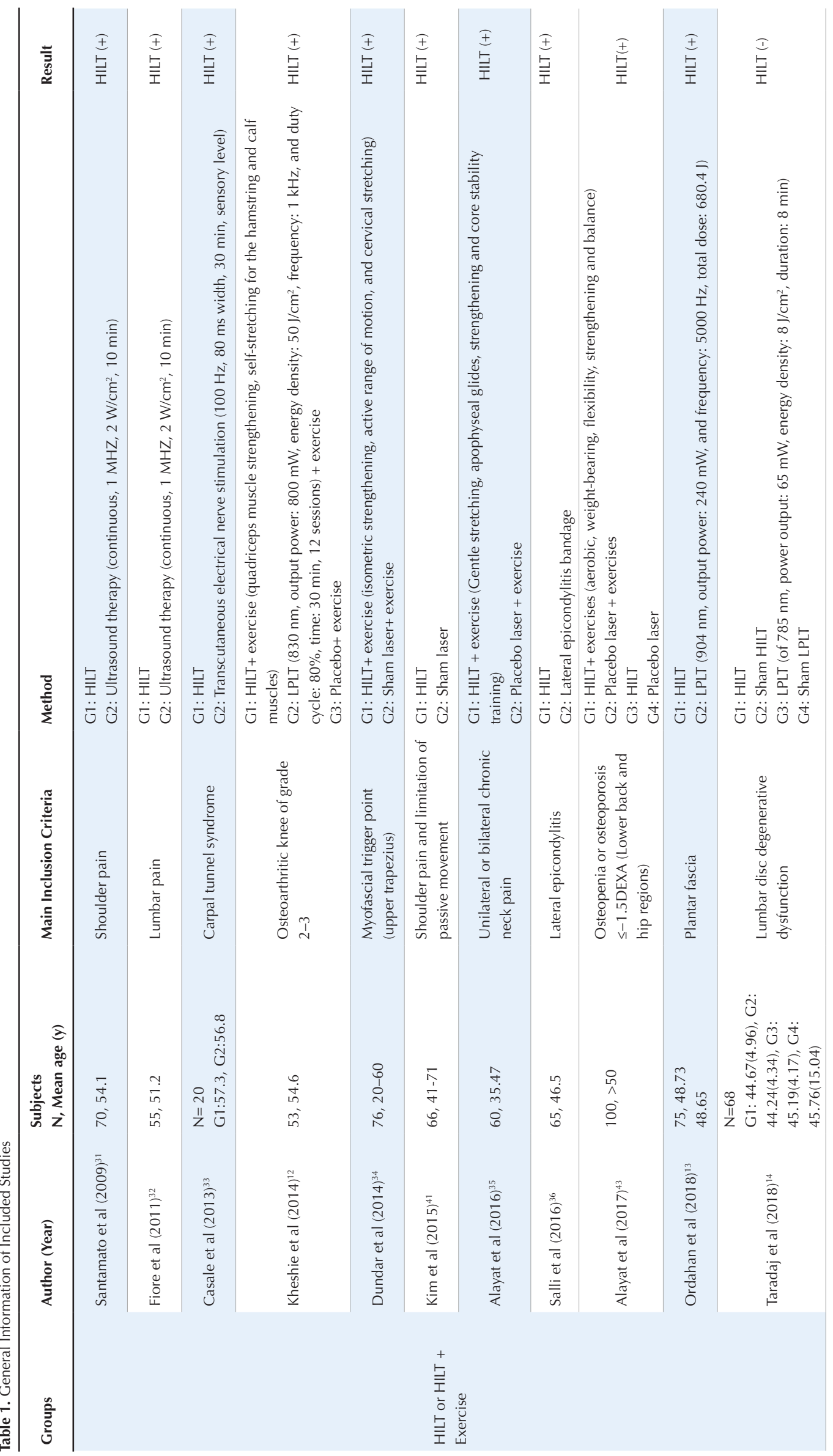




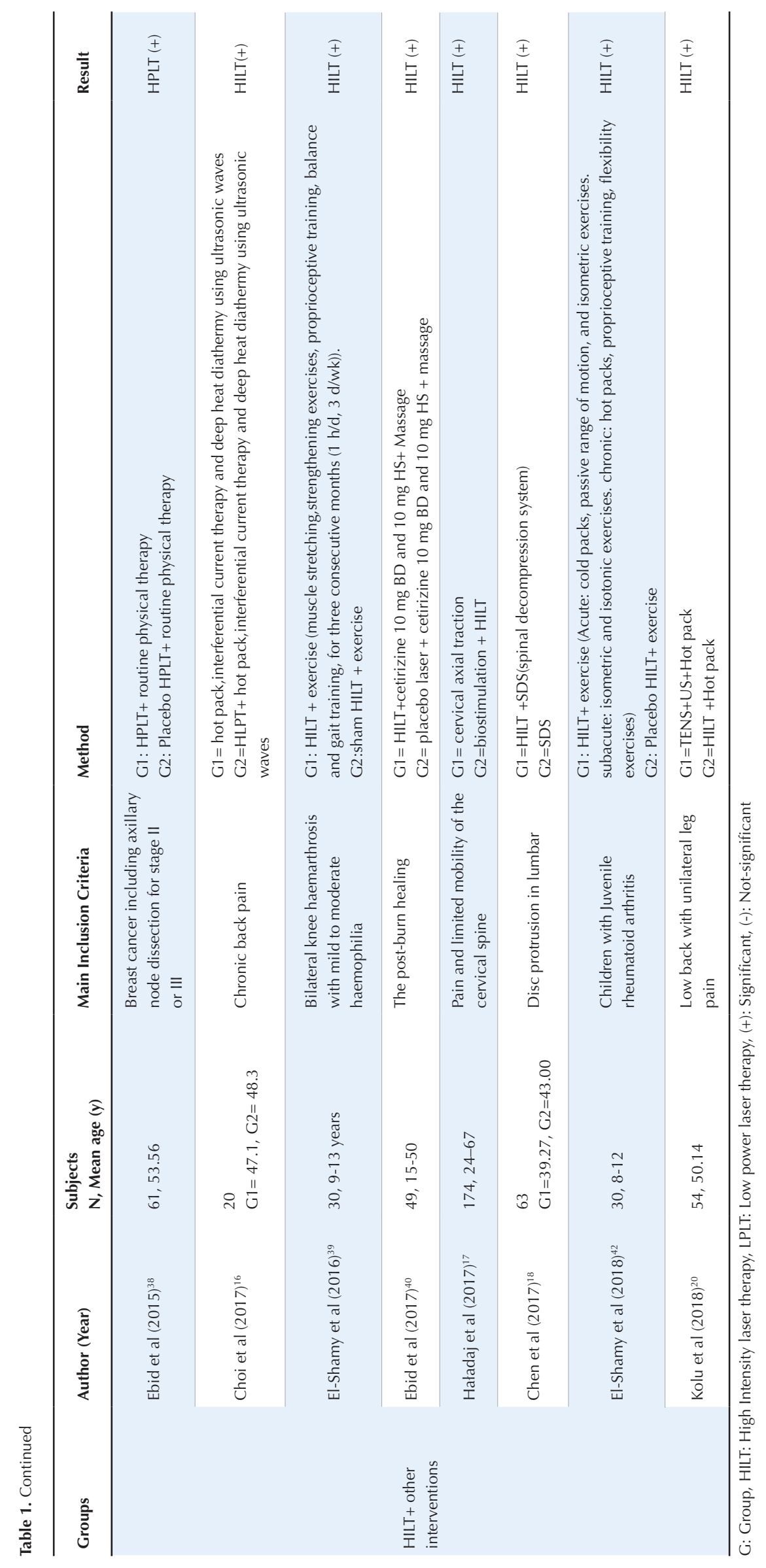




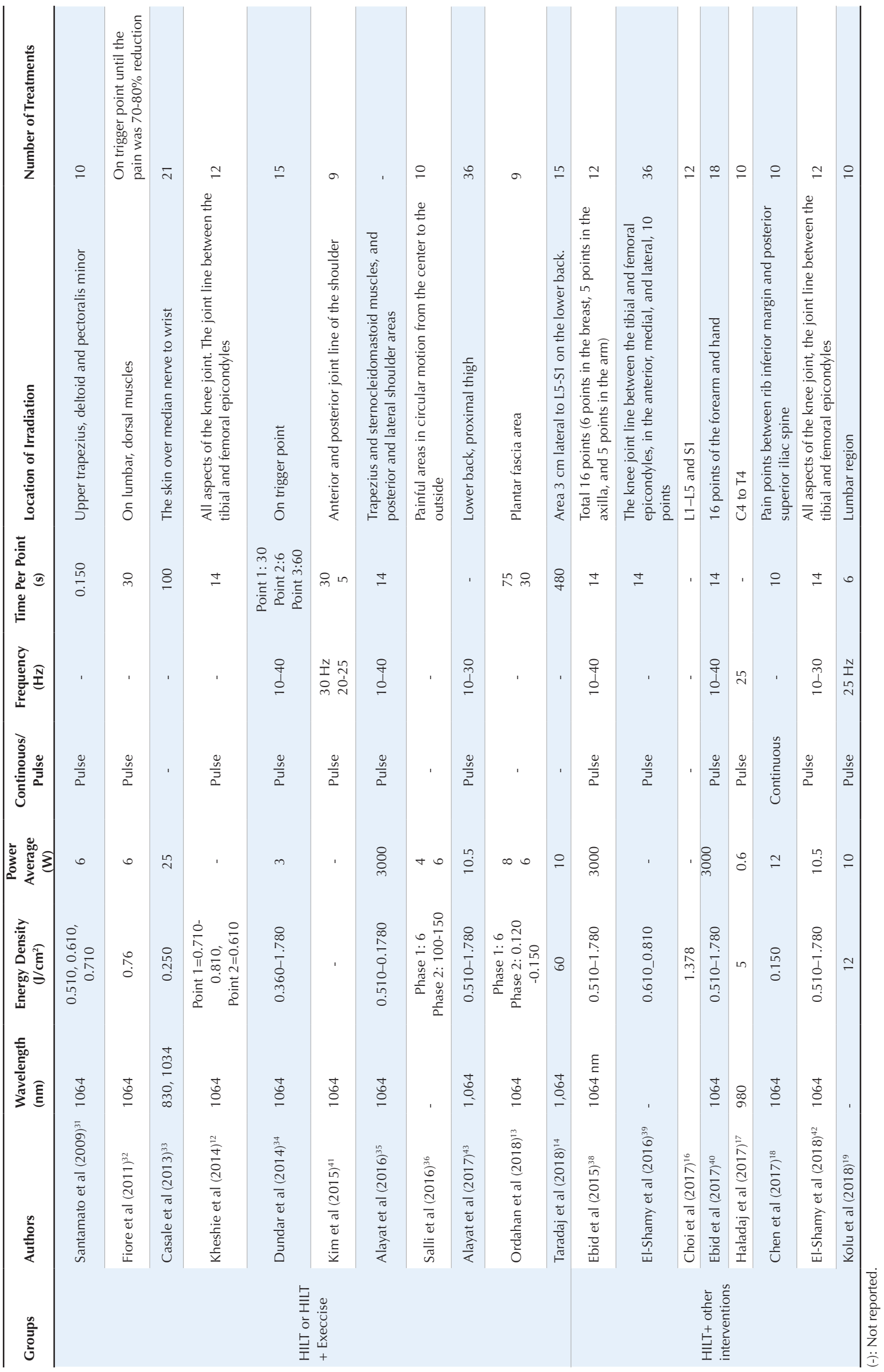




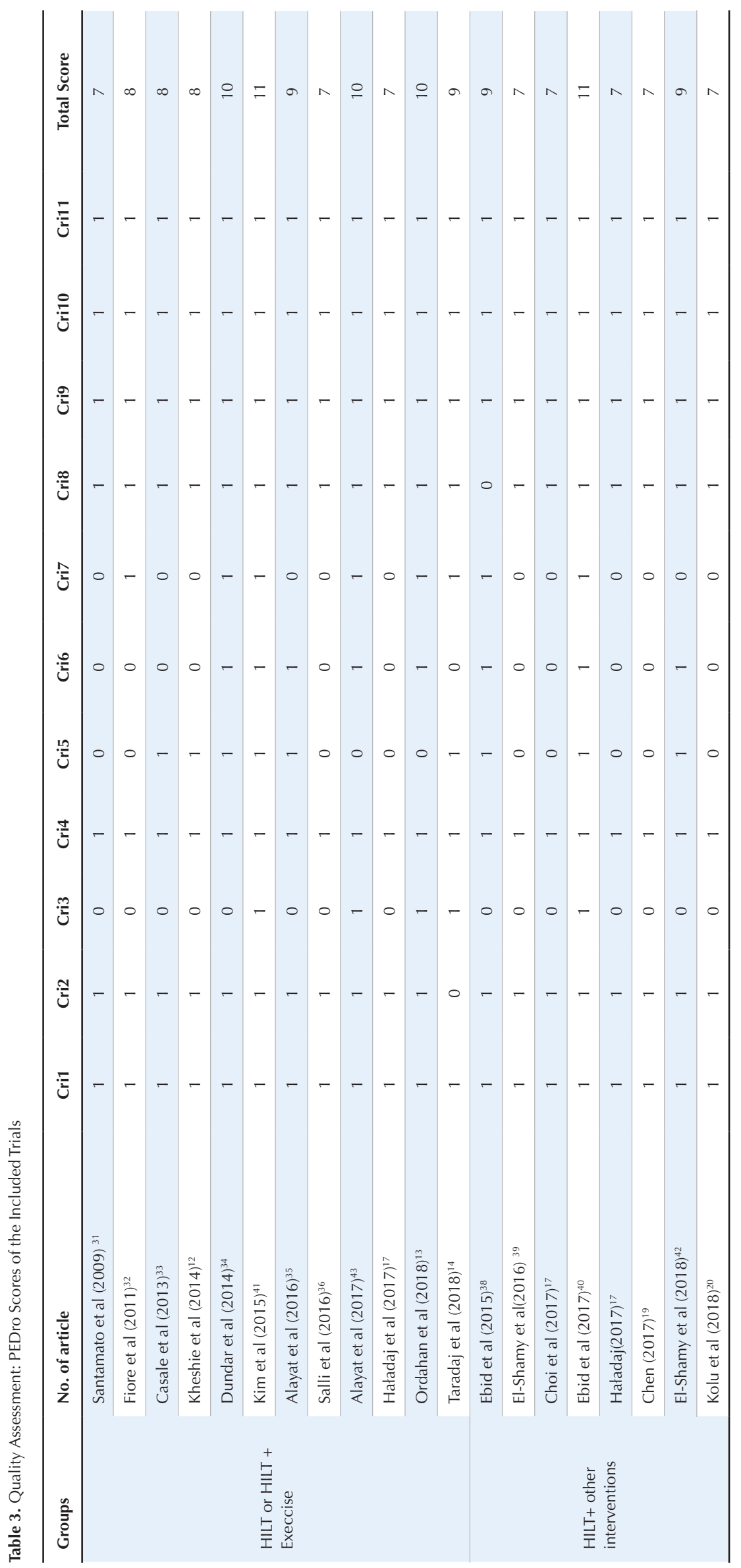


Table 4. The Function of the Laser Beam (Most Effect to Less Effect) on the Diseases

\begin{tabular}{|c|c|c|}
\hline Groups & Author (Year) & Disease \\
\hline \multirow{11}{*}{ HILT or HILT + Execcise } & Alayat et al $(2017)^{43}$ & Osteopenia or osteoporosis (Lower back and hip regions) \\
\hline & Ordahan et al $(2018)^{13}$ & Plantar fascia \\
\hline & Kheshie et al $(2014)^{12}$ & Osteoarthritic knee of grade $2-3$ \\
\hline & Alayat et al $(2016)^{35}$ & Unilateral or bilateral chronic neck pain \\
\hline & Casale et al $(2013)^{33}$ & Carpal tunnel syndrome \\
\hline & Dundar et al $(2014)^{34}$ & Myofascial trigger point (upper trapezius) \\
\hline & Fiore et al (2011) ${ }^{32}$ & Lumbar pain \\
\hline & Santamato et al $(2009)^{31}$ & Shoulder pain \\
\hline & Kim et al (2015) ${ }^{41}$ & Shoulder pain and limitation of passive movement \\
\hline & Taradaj et al $(2018)^{14}$ & Lumbar disc degenerative dysfunction \\
\hline & Salli et al $(2016)^{36}$ & Lateral epicondylitis \\
\hline \multirow{8}{*}{ HILT+ other interventions } & Choi et al $(2017)^{16}$ & Chronic back pain \\
\hline & El-Shamy et al $(2018)^{42}$ & Children with Juvenile rheumatoid arthritis \\
\hline & El-Shamy et al $(2016)^{39}$ & Bilateral knee haemarthrosis with mild to moderate haemophilia \\
\hline & Ebid et al $(2017)^{40}$ & The post-burn healing \\
\hline & Ebid et al $(2015)^{38}$ & Breast cancer including axillary node dissection for stage II or III \\
\hline & Chen et al $(2017)^{18}$ & Disc protrusion in lumbar \\
\hline & Haładaj et al $(2017)^{17}$ & Pain and limited mobility of the cervical spine \\
\hline & Kolu et al $(2018)^{20}$ & Low back with unilateral leg pain \\
\hline
\end{tabular}

on different mechanisms and it seems that we should apply more irradiance of laser therapy in chronic pain conditions. ${ }^{50,51}$ The treatment area of the scanner lasers is a major contributor to laser efficacy, indicated by some studies. ${ }^{13,18,36,39}$ Others just mentioned the probe size which is not as important as the treatment area. The etiology and diagnosis of the disease are important when using a laser. As an example, laser therapy cannot resolve the main sources of pain resulting from myofascial pain syndrome as the pain in these patients is caused by the development of the taut bands in the muscles. ${ }^{34}$

The limitation of this study is related to the fact that musculoskeletal disorders are wide-range disorders and thus it is better to limit this systematic review to some topics such as low back pain, shoulder pain or knee osteoarthritis in future studies.

\section{Conclusion}

Our results suggest that it is still early to determine if HILT may be an effective non-invasive agent in the management of musculoskeletal pain although there are indications that it may have benefits in some conditions depending on the treatment parameters. Adding related co-interventions to HILT may enhance the beneficial effects of laser therapy. It is clear from our findings that long-term, randomized controlled trials with an appropriate methodological design are needed to determine the effect of HILT on pain in a range of musculoskeletal conditions not covered by this review, or in some conditions that methodological matters made it difficult to evaluate the outcomes.

\section{Ethical Considerations}

Not applicable.

\section{Conflict of Interests}

The authors declare no conflict of interest.

\section{Funding}

According to the fact that this is a systematic review, no consent form was required. This study was supported by research and technology deputy of Guilan University of Medical Sciences.

\section{Acknowledgements}

Special thanks to Professor Mohammad Ali Mohseni Bandpei for outstanding help in revision. Also, the authors would like to thank clinical research development unit of Poursina hospital, Guilan University of Medical Sciences, Rasht, Iran.

\section{Supplementary Materials}

Supplementary file 1 contains Table S1.

\section{References}

1. Kim GJ, Choi J, Lee S, Jeon C, Lee K. The effects of high intensity laser therapy on pain and function in patients with knee osteoarthritis. J Phys Ther Sci. 2016;28(11):31979. doi: $10.1589 /$ jpts.28.3197

2. Conforti M, Fachinetti GP. High power laser therapy treatment compared to simple segmental physical rehabilitation in whiplash injuries $\left(1^{\circ}\right.$ and $2^{\circ}$ grade of the Quebec Task Force classification) involving muscles and 
ligaments. Muscles Ligaments Tendons J. 2013;3(2):106-11. doi: $10.11138 / \mathrm{mltj} / 2013.3 .2 .106$

3. Tabatabai SMR, Bashardoust Tajali S, Attarbashi Moghadam B, Mir SM. Effects of high-Power diode laser irradiation combined with electrical stimulation on wrist pain and function following carpal tunnel syndrome. J Clin Physiother Res. 2016;1(2):61-7. doi: 10.22037/jcpr.2016.04

4. Alayat MS, Elsodany AM, El Fiky AA. Efficacy of high and low level laser therapy in the treatment of Bell's palsy: a randomized double blind placebo-controlled trial. Lasers Med Sci. 2014;29(1):335-42. doi: 10.1007/s10103-0131352-z

5. Cotler HB, Chow RT, Hamblin MR, Carroll J. The use of low level laser therapy (LLLT) for musculoskeletal pain. MOJ Orthop Rheumatol. 2015;2(5). doi: 10.15406/ mojor.2015.02.00068

6. Ezzati K, Fekrazad R, Raoufi Z. The effects of photobiomodulation therapy on post-surgical pain. J Lasers Med Sci. 2019;10(2):79-85. doi: 10.15171/jlms.2019.13

7. Thabet AAE, Mahran HG, Ebid AA, Alshehri MA. Effect of pulsed high intensity laser therapy on delayed caesarean section healing in diabetic women. J Phys Ther Sci. 2018;30(4):570-5. doi: 10.1589/jpts.30.570

8. Boyraz I, Yildiz A, Koc B, Sarman H. Comparison of high-intensity laser therapy and ultrasound treatment in the patients with lumbar discopathy. Biomed Res Int. 2015;2015:304328. doi: 10.1155/2015/304328

9. Thabet AAE, Alshehri MA. Effect of Pulsed high-Intensity laser therapy on pain, adhesions, and quality of Life in women having endometriosis: A randomized controlled trial. Photomed Laser Surg. 2018;36(7):363-9. doi: 10.1089/ pho.2017.4419

10. Thabet AAE, Elsodany AM, Battecha KH, Alshehri MA, Refaat B. High-intensity laser therapy versus pulsed electromagnetic field in the treatment of primary dysmenorrhea. J Phys Ther Sci. 2017;29(10):1742-8. doi: 10.1589/jpts.29.1742

11. Pekyavas NO, Baltaci G. Short-term effects of highintensity laser therapy, manual therapy, and Kinesio taping in patients with subacromial impingement syndrome. Lasers Med Sci. 2016;31(6):1133-41. doi: 10.1007/s10103016-1963-2

12. Kheshie AR, Alayat MSM, Ali MM. High-intensity versus low-level laser therapy in the treatment of patients with knee osteoarthritis: a randomized controlled trial. Lasers Med Sci. 2014;29(4):1371-6. doi: 10.1007/s10103-0141529-0

13. Ordahan B, Karahan AY, Kaydok E. The effect of highintensity versus low-level laser therapy in the management of plantar fasciitis: a randomized clinical trial. Lasers Med Sci. 2018;33(6):1363-9. doi: 10.1007/s10103-018-2497-6

14. Taradaj J, Rajfur K, Shay B, Rajfur J, Ptaszkowski K, Walewicz $\mathrm{K}$, et al. Photobiomodulation using highor low-level laser irradiations in patients with lumbar disc degenerative changes: disappointing outcomes and remarks. Clin Interv Aging. 2018;13:1445-55. doi: 10.2147/ CIA.S168094

15. Song HJ, Seo HJ, Lee Y, Kim SK. Effectiveness of highintensity laser therapy in the treatment of musculoskeletal disorders: A systematic review and meta-analysis of randomized controlled trials. Medicine (Baltimore).
2018;97(51): e13126. doi: 10.1097/MD.0000000000013126

16. Choi HW, Lee J, Lee S, Choi J, Lee K, Kim BK, et al. Effects of high intensity laser therapy on pain and function of patients with chronic back pain. J Phys Ther Sci. 2017;29(6):107981. doi: 10.1589/jpts.29.1079

17. Haładaj R, Pingot M, Topol M. The effectiveness of cervical spondylosis therapy with Saunders traction device and high-intensity laser therapy: a randomized controlled trial. Medical science monitor: Med Sci Monit. 2017;23:335-42. doi: 10.12659/MSM.899454

18. Chen L, Liu D, Zou L, Huang J, Chen J, Zou Y, et al. Efficacy of high intensity laser therapy in treatment of patients with lumbar disc protrusion: A randomized controlled trial. J Back Musculoskelet Rehabil. 2018;31(1):191-6. doi: 10.3233/BMR-170793

19. Thoomes EJ, Scholten-Peeters W, Koes B, Falla D, Verhagen AP. The effectiveness of conservative treatment for patients with cervical radiculopathy: a systematic review. Clin J Pain. 2013;29(12):1073-86. doi: 10.1097/AJP.0b013e31828441fb

20. Kolu E, Buyukavci R, Akturk S, Eren F, Ersoy Y. Comparison of high-intensity laser therapy and combination of transcutaneous nerve stimulation and ultrasound treatment in patients with chronic lumbar radiculopathy: A randomized single-blind study. Pak J Med Sci. 2018;34(3):530-4. doi: 10.12669/pjms.343.14345

21. Bjordal JM, Couppé C, Chow RT, Tunér J, Ljunggren EA. A systematic review of low level laser therapy with locationspecific doses for pain from chronic joint disorders. Aust J Physiother. 2003;49(2):107-16. doi: 10.1016/s00049514(14)60127-6

22. Santuzzi CH, Buss HF, Pedrosa DF, Freire MO, Nogueira BV, Gonçalves WL. Combined use of low level laser therapy and cyclooxygenase-2 selective inhibition on skin incisional wound reepithelialization in mice: a preclinical study. An Bras Dermatol. 2011;86(2):278-83. doi: 10.1590/ s0365-05962011000200011

23. Huang Z, Chen J, Ma J, Shen B, Pei F, Kraus VB. Effectiveness of low-level laser therapy in patients with knee osteoarthritis: a systematic review and meta-analysis. Osteoarthritis Cartilage. 2015;23(9):1437-44. doi: 10.1016/j. joca.2015.04.005

24. Mårdh A, Lund I. High power Laser for treatment of Achilles tendinosis-a single blind randomized placebo controlled clinical study. J Lasers Med Sci. 2016;7(2):92-8. doi: $10.15171 /$ jlms.2016.16

25. Angelova A, Ilieva EM. Effectiveness of high intensity laser therapy for reduction of pain in knee osteoarthritis. Pain Res Manag. 2016;2016 :9163618. doi: 10.1155/2016/9163618

26. Akkurt E, Kucuksen S, Yilmaz H, Parlak S, Sallı A, Karaca G. Long term effects of high intensity laser therapy in lateral epicondylitis patients. Lasers Med Sci. 2016;31(2):249-53. doi: 10.1007/s10103-015-1841-3

27. Štiglić-Rogoznica N, Stamenković D, Frlan-Vrgoč L, Avancini-Dobrović V, Schnurrer-Luke Vrbanić T. Analgesic effect of high intensity laser therapy in knee osteoarthritis. Coll Antropol. 2011;35(2):183-5.

28. Tomazoni SS, Costa LDCM, de Souza Guimarães L, Araujo AC, Nascimento DP, de Medeiros FC, et al. Effects of photobiomodulation therapy in patients with chronic non-specific low back pain: protocol for a randomised placebo-controlled trial. BMJ Open. 2017;7(10):e017202. 
doi: 10.1136/bmjopen-2017-017202

29. White PF, Zafereo J, Elvir-Lazo OL, Hernandez H. Treatment of drug-resistant fibromyalgia symptoms using high-intensity laser therapy: a case-based review. Rheumatol Int. 2018;38(3):517-23. doi: 10.1007/s00296017-3856-5

30. Costello JA. The long term management of diabetic neuropathy with high power laser therapy (HPLT). Aspenlasers website; 2009.

31. Santamato A, Solfrizzi V, Panza F, Tondi G, Frisardi V, Leggin BG, et al. Short-term effects of high-intensity laser therapy versus ultrasound therapy in the treatment of people with subacromial impingement syndrome: a randomized clinical trial. Phys Ther. 2009;89(7):643-52. doi: 10.2522/ptj.20080139

32. Fiore P, Panza F, Cassatella G, Russo A, Frisardi V, Solfrizzi $\mathrm{V}$, et al. Short-term effects of high-intensity laser therapy versus ultrasound therapy in the treatment of low back pain: a randomized controlled trial. Eur J Phys Rehabil Med. 2011;47(3):367-73.

33. Casale R, Damiani C, Maestri R, Wells CD. Pain and electrophysiological parameters are improved by combined 830-1064 high-intensity LASER in symptomatic carpal tunnel syndrome versus Transcutaneous Electrical Nerve Stimulation. A randomized controlled study. Eur J Phys Rehabil Med. 2013;49(2):205-11.

34. Dundar U, Turkmen U, Toktas H, Solak O, Ulasli AM. Effect of high-intensity laser therapy in the management of myofascial pain syndrome of the trapezius: a double-blind, placebo-controlled study. Lasers Med Sci. 2015;30(1):32532. doi: 10.1007/s10103-014-1671-8

35. Alayat MS, Mohamed AA, Helal OF, Khaled OA. Efficacy of high-intensity laser therapy in the treatment of chronic neck pain: a randomized double-blind placebo-control trial. Lasers Med Sci. 2016;31(4):687-94. doi: 10.1007/ s10103-016-1910-2

36. Salli A, Akkurt E, Izki AA, Şen Z, Yilmaz H. Comparison of high intensity laser and epicondylitis bandage in the treatment of lateral epicondylitis. Arch Rheumatol. 2016;31(3):234-8. doi: 10.5606/ArchRheumatol.2016.5793

37. Alayat MS, Aly TH, Elsayed AE, Fadil AS. Efficacy of pulsed Nd: YAG laser in the treatment of patients with knee osteoarthritis: a randomized controlled trial. Lasers Med Sci. 2017;32(3):503-11. doi: 10.1007/s10103-017-2141-x

38. Ebid AA, El-Sodany AM. Long-term effect of pulsed highintensity laser therapy in the treatment of post-mastectomy pain syndrome: a double blind, placebo-control, randomized study. Lasers Med Sci. 2015;30(6):1747-55. doi: 10.1007/s10103-015-1780-Z

39. El-Shamy SM, Abdelaal AAM. Efficacy of pulsed highintensity laser therapy on pain, functional capacity, and gait in children with haemophilic arthropathy. Disabil Rehabil. 2018;40(4):462-8. doi: 10.1080/09638288.2016.1261416
40. Ebid AA, Ibrahim AR, Omar MT, El Baky AM. Longterm effects of pulsed high-intensity laser therapy in the treatment of post-burn pruritus: a double-blind, placebo-controlled, randomized study. Lasers Med Sci. 2017;32(3):693-701. doi: 10.1007/s10103-017-2172-3

41. Kim SH, Kim YH, Lee HR, Choi YE. Short-term effects of high-intensity laser therapy on frozen shoulder: a prospective randomized control study. Man ther. 2015;20(6):751-7. doi: 10.1016/j.math.2015.02.009

42. El-Shamy SM, Alayat MSM, Abdelgalil AA, Alshehri MA. Long-Term Effect of Pulsed Nd: YAG Laser in the Treatment of Children with Juvenile Rheumatoid Arthritis: A Randomized Controlled Trial. Photomed Laser Surg. 2018;36(8):445-51. doi: 10.1089/pho.2018.4444

43. Alayat MSM, Abdel-Kafy EM, Elsoudany AM, Helal OF, Alshehri MA. Efficacy of high intensity laser therapy in the treatment of male with osteopenia or osteoporosis: a randomized placebo-controlled trial. J Phys Ther Sci. 2017;29(9):1675-9. doi: 10.1589/jpts.29.1675.

44. Cohen J. Statistical Power Analysis for the Behavioral Sciences. 2nd ed. Hillsdale: Lawrence Erlbaum Associates; 1988.

45. Svensson E. Ordinal invariant measures for individual and group changes in ordered categorical data. Stat Med. 1998;17(24):2923-36. doi: 10.1002/(sici)10970258(19981230)17:24<2923::aid-sim104>3.0.co;2-\#

46. Avdic A, Svensson E. Svenssons method 1. 1st ed. Örebro 2010 Interactive software supporting Svenssons method. Accessed from http://avdic.se/svenssonsmetod.html.

47. Holm S. A simple sequentially rejective multiple test procedure. SCAND J STAT. 1979;6(2):65-70.

48. Keller A, Hayden J, Bombardier C, van Tulder M. Effect sizes of non-surgical treatments of non-specific low-back pain. Eur Spine J. 2007;16(11):1776-88. doi: 10.1007/ s00586-007-0379-x

49. McAlindon TE, Bannuru RR, Sullivan MC, Arden NK, Berenbaum F, Bierma-Zeinstra SM, et al. OARSI guidelines for the non-surgical management of knee osteoarthritis. Osteoarthritis Cartilage. 2014;22(3):363-88. doi: 10.1016/j. joca.2014.01.003

50. Ezzati K, Laakso EL, Saberi A, Yousefzadeh Chabok S, Nasiri E, Bakhshayesh Eghbali B. A comparative study of the dose-dependent effects of low level and high intensity photobiomodulation (laser) therapy on pain and electrophysiological parameters in patients with carpal tunnel syndrome: a randomized controlled trial. Eur J Phys Rehabil Med. 2019. doi: 10.23736/S1973-9087.19.05835-0

51. Bjordal JM, Johansen O, Holm I, Zapffe K, Nilsen EM. The Effectiveness of Physical Therapy, Restricted to Electrotherapy and Exercise, for Osteoarthritis of the Knee. Oslo, Norway: Knowledge Centre for the Health Services at The Norwegian Institute of Public Health (NIPH); 2004. 